community have been disorganized or reorganized under the leadership of the municipal governments. The endogenous self-organizations changed roles to a pseudo-organization of the local government.

How did this institutional intervention result in weakening of the self-reliance capabilities of communities? The main causes can be found in the three aspects. First, there was a lack of an idea of what a so called Kaso area ought to be. The target of policy has been focused on population matters, which was a sort of reminiscence of pre-Kaso periods. Therefore, little attention has been devoted to empowerment of communities. This was caused by the inadequate definition of Kaso. In the strict sense of the word, Kaso does not mean merely depopulation itself. Kaso should be defined within a structural perspective: regional problematic situations, arising from rapid depopulation of local communities, make it difficult to maintain a national standard level of life quality in rural areas; the depopulation must be qualified as one which is induced by rapid industrialization through city-oriented national policies. Secondly, the means of policies was inadequate. Most of the policy means have been designed to keep a fair distribution of resources such as subsidies with little attention to who could do that and how it could be done.

The author argues that social vitality should be a new criterion for empowerment of Kaso areas, rather than economic aspects. An endogenous self-organization which functions as a substantial social unit for rural development can be one of the criteria to measure social vitality. Moreover, there is a very special sphere that exists in communities which does not exist at market and/or administration level. This sphere is the distribution of benefits by policy implementation or the mediation of social conflict. That is why in rural development the role of endogenous self-organization is so important.

\title{
Present Situation and Problems of the Geoecological Studies on Japanese Mountains
}

\section{The Aim of the Symposium}

YOKOYAMA Hideji

Kyushu Sangyo University

The term 'landscape ecology' was devised by Carl Troll (1939). Later, he coined the word 'geoecology' to describe the same field of study (1968). These studies made advances in Europe from the 1960s. In Japan, S. Sugiura (1974) and H. Yokoyama (1979) introduced the studies of landscape ecology and geoecology. These studies in Japan made advances in the disciplines of geography, ecology and landscape architecture from the 1990s.

In April 1996, we established a research group on 'geoecology' in the Association of Japanese Geographers. The geoecological studies of our group members was mainly researches of mountainous areas, as in Europe and USA. We conducted research on the analysis of the geoecosystem of mountains in Hokkaido and cen-

\author{
tral Japan.
}

This symposium was organized by our research group. The aim is to demonstrate the present situation of geoecological studies on Japanese mountains, and to discuss the problems of these studies.

\section{A Perspective on Vegetation Patterns and Processes as a Basis for Managing Mountain Ecosystems}

TAKAOKA Sadao

Senshu University

This paper examined origins and spatiotemporal changes in vegetation patterns as a basis for managing mountain ecosystems with special reference to environmental resources and disturbance regimes.

Environmental resources and natural disturbances are the essential factors that create a patch-mosaic structure of vegetation. Environ- 
mental resources control physiological conditions for plants, while disturbances destroy existing vegetation and allow a chance of regeneration. Environmental resources influence species composition, and disturbances create several patches in various successional stages. Thus, a vegetation landscape can be recognized as being composed of two types of vegetation patches; environmental and disturbance patches. Environmental patches of vegetation are caused by the spatially heterogeneous distribution of environmental resources. On the other hand, disturbance patches result from disturbances of a certain area.

In mountainous areas, the operation of these two factors is controlled by landform. Spatial distribution of environmental conditions varies with different slope aspect and topographic positions. Intensity and frequency of natural disturbances are also increased or decreased by landform: areal extent of disturbed and sheltered sites is closely related with topographic positions. Further, landform itself changes and consequently disturbs vegetation on the former landform. Understanding of the relationships between landform and these operations can make it possible to show potential distribution of vegetation mosaics and to predict how it will change in the future.

Spatio-temporal changes of vegetation can be characterized by difference in persistence of these two types of patches. An environmental patch does not change unless environmental conditions change at the site, reflecting the stability of the environmental resources. In contrast, a disturbance patch changes relatively rapidly by ecological succession, and is to be replaced with a climax-stage patch.

Mountain ecosystems should be managed with consideration of the characteristics of vegetation dynamics. Understanding of natural disturbance regimes and patchiness of environmental resources has to be further developed. However, it is not easy to comprehend a polygenetic vegetation structure. Some vegetation patches may be formed under the past disturbance regimes, and past climatic conditions may be imprinted on the present-day structure of vegetation patterns owing to lags in vegetation responses to changing environ- ments. More researches on vegetation as a legacy of the long-term interplay of all the environmental factors are needed to improve our understanding on patterns and processes of vegetation.

\section{What is the Contribution of Climatology to the Geoecological Research on Japanese Moun- tains?}

UMEMOTO Tohru

Meiji University

Most geoecological studies of the Japanese mountains have been presented by geomorphologists, botanists and vegetation geographers. They always pointed out the importance of the characteristic conditions of the Japanese mountain climate, such as strong winds, heavy snowfalls, and the huge amount of snow-cover.

We can find very little contribution by Japanese climatologists, but they have carried out many field activities in Japanese mountains. Their efforts have been concentrated on two subjects: 1) local thermal conditions and circulation systems, 2) 'Kikou-keikan' (climatic landscapes) which means field elements such as wind-shaped trees or Krummholz indicating some extreme climatic conditions.

The author explained the contribution and aims of Japanese climatologists to the geoecological research on the Japanese mountains. His presentation contained the following four discussion points:

1. Reconsidering spatial (and temporal) scale of the climate over the Japanese mountains: The spatial scale is largely different from the great mountain systems such as the Alps, the Rockies and the Andes, so that we should consider firstly the macro-scale climate over the Japanese Islands. Secondly, we should recognize what components of the atmospheric systems are the controlling factors of geoecological variables.

2. Evaluating the importance of severe storms (tropical and extratropical cyclones) as eventmakers: The most important local feature is the strong westerlies with cold surges from the continent in winter, but the synoptic and subsynoptic scale atmospheric disturbances are also important. The northwestern part of the Pacific Ocean is the most active area of extratropical 
cyclones. Moreover, tropical cyclones may bring about the total destruction of local geoecosystems by strong winds and heavy rainfalls. Therefore, these disturbances are considered to be repeating event-makers.

3. Performing the intensive field meteorological observation: We must seek a reliable observation method of near surface wind profiles even within the thick bush canopy layers.

4. Encouraging meteorologists and ecologists to construct or tune up a realistic model which can simulate the geoecological phenomena: We need a high resolution local atmospheric model for complex terrain that will be the first step of a geoecological simulation model.

\section{Geoecological Studies around the Jounen- nokkoshi Pass, Northern Japanese Alps}

HASEGAWA Hirohiko,*

TAKAHASHI Nobuyuki,**

SASAKI Akihiko,*** and KATO Yuzuru*

*Meiji University

**Hokkai-gakuen University

***Tohoku University

The formations of alpine and subalpine landscapes on the Japanese high mountains have been strongly influenced by Late Quaternary climatic change, and the landscapes still continue to change under the present environmental conditions. The authors clarified the landscape development history around the forest limit of Jounen-nokkoshi Pass, northern Japanese Alps, since the Last Glacial period.

On the windward (western side) slope of the pass, landscapes are classified into the following three major units; northern, central, and southern landscape units. The northern landscape unit consists of periglacial smooth slopes (PSS) with a superficial layer composed of granitic sands with angular gravels. The landscape unit is further subdivided into three units, which are wind-blown bare ground, younger PSS covered with pinus pumila community and older PSS covered with subalpine coniferous forest. Formative stages of the younger and older PSS correspond to the Late Glacial and Last Glacial Maximum, respectively.

The boundaries of each subunit are formed mainly by either the continuous front risers of solifluction sheets or the scars caused by wind erosion.

The central landscape unit consists of PSS, whose superficial layer is composed of volcanic angular gravels with fine matrix. This landscape unit is also subdivided into three subunits as well as in the northern unit. The amount of wind-blown bare ground area, however, is smaller than that of the northern unit, because the larger size of the superficial materials easily leads to slope stability and invasion of vegetation.

The southern landscape unit consists of younger PSS with a superficial layer composed of granitic boulders without fine matrix. The PSS are mainly covered with wind-blown dwarf scrubs and pinus pumila community and partly non-vegetated. Many solifluction lobes, which have risers 20 to $200 \mathrm{~cm}$ high, occur on this slope. Vegetational conditions, such as vegetation coverage, component of species and height of vegetation, on the slopes are controlled by difference in snow depth in winter which is correlated with the conditions of micro-topography and prevailing wind.

From the above mentioned, the distribution of the major landscape units around the windward slope of Jounen-nokkoshi Pass is primarily determined by the characteristics of surface materials depending on geological conditions. Secondly, the subunits are decided by the difference in landform development after the LGM in the northern and central landscape units, and by the distribution of micro-topography such as solifluction lobes in the southern landscape unit.

On the other hand, the landscapes of the lee side slope are divided into four units based on topographical conditions; crest slopes, steep valley-side slopes, valley-bottom slopes and fossil snowpatch hollows. Distribution of these landscape units is decided not only by the difference in slope stability since the Last Glacial period but also by the present snowdrift conditions such as snow depth and strength of snow glide. 
Distribution of Ground Ice and Vegetation on the Block Slope in Shikaribetsu Volcano Group, Central Hokkaido

SAWADA Yuki

Hokkaido University

In the eastern part of Hokkaido Island, the "extra-zonal" permafrost survives sporadically at the foot of block slopes far below the tree line. It induces unpredictable low ground temperatures, enabling alpine plants such as Ledum palustre and Emretrum nignum to survive in lower altitudes. The present study evaluates the "rules of thumb" which predict the permafrost existence based on the presence of alpine vegetation on the block slopes. The studied block slope is situated on the upper-most part of Mt. Nishi-nupukaushinupuri (1251 m a.s.1.) in the southern part of Mt. Daisetsu National park. Forest (mainly Picea glehnii) covers roughly half of the block slope. Wind holes, through which cold air blows in summer and fall, are distributed in the lower part of the slope, dominated by the alpine plants and Shagnum mat.

To confirm the existence of permafrost, a DC resistivity imaging was carried out in the block slope area. This method can obtain a large contrast of resistivity between unfrozen sediments and ground ice or ice-rich frozen sediments, thus enabling the distinction of permafrost body via 2D tomography. A multielectrode system (30 electrodes at $5 \mathrm{~m}$ spacing) was used, resulting in a $150 \mathrm{~m}$ survey line parallel to the transverse line of the slope aspect. The survey line started at non-block slope adjacent to the block slope, and terminated in middle part of the block slope. A set of measurements consisted of 414 data points (WennerSchlumberger array). Results of the 2D model interpretation show a good contrast of resistivity values; high resistivity values $(500-1000$ $\mathrm{k} \Omega$ ) ware detected to the depth of $20 \mathrm{~m}$ in the lowermost part of the block slope, while low values $(16-34 \Omega)$ were found in the middle slope and in non-block slope. In the lower slope, where perennial ice has been detected by a pit survey, the open-space between the blocks was filled with ice. This indicates that such icefilling layer can exist at considerable depths. The high values area in the lower slope probably corresponds to the ice-cemented layer; i.e. permafrost body. This area is situated at the foot of the block slope where alpine plants and Sphagnum sp. are predominant, indicating that the "rules of thumb" are applicable for the block slope.

\section{Hiking Trail Erosion in the Southern Part of the Tanzawa Mountains}

NAKAMURA Yosuke

Komazawa University

This report summarizes the result of investigation on the hiking trail erosion in Mt. Tonodake of the southern Tanzawa Mountains.

The hiking trails around Mt. Tonodake are used by many hikers. According to the questionnaire at the summit of Mt. Tonodake, the trails through Okura ridge and Omote ridge are most frequently utilized. According to the aerial photo, the hiking trail was covered by grassland and no erosion was observed in 1947. But the aerial photo in 1980 reveals that bare ground became larger than ever. Sheet erosion had occurred around the summit of the mountain. The distribution of this bare ground generally corresponds to the area of convex gentle slope or flat landform along the mountain ridges. The cross section survey of the hiking trail at the sites of degradation shows that about $4 \mathrm{~m}$ of gully erosion has occurred to the maximum. The gully erosion has often occurred in the area covered with a thick Kanto Loam and Kuroboku soil. Considering the relation between the state of vegetation and horizontal erosion, it is estimated that horizontal erosion tends to advance easily in grassland.

The conditions of soil erosion after installation of $\log$ stairs are also investigated in the Omote ridge trail where severe degradation has occurred. $59 \%$ of log stairs has been ruined in five years, since its installation. The erosion by stepping out of log stairs is found in the grassland. As for the degradation process of log stairs, the following three types are observed: (1) Erosion caused by ruins from lower weak towards upper parts, (2) Erosion of bare soil on the front of stair with the surface runoff, and (3) Compound type of above two erosions.

In order to perform sustainable conservation, reinforcement of weak stairs, the change to water cut construction, and increase of mainte- 
nance persons is required.

\section{Need for Geoecological Approach to Solve Mountain Environmental Problems}

WATANABE Teiji

Hokkaido University

A collaborative geoecological research project has been conducted in the Kanchanjunga Conservation Area, far eastern Nepal. This project was initiated by the academic exchange program between Hokkaido University, Japan and Tribhuvan University, Nepal in 1997. The final goal of the project is to establish ecotourism; however, the project centers on physical scientific aspects, such as melting glaciers and permafrost, and wildlife conservation.

To fulfill these goals, the first phase of the project from 1997 to 2000 , focused on the collection of basic data related to geomorphic dynamics, such as permafrost, hazards, and glacier-related phenomena, and wildlife habitat. Air temperatures at one-hour intervals have been monitored at the altitudes of $3,407 \mathrm{~m}, 4,755 \mathrm{~m}$, and $6,012 \mathrm{~m}$. Mountain permafrost distribution was monitored by the methods of electric resistivity sounding, seismic sounding, and ground temperature and BTS measurements. The lateral moraines of the major valley glaciers, such as the Kanchanjunga Glacier, have landslides. The landslides have been developing even today, although the cause is not yet clear. They may disturb the development of safe ecotourism at some places. Vertical air photographs in 1992 were interpreted to identify the distribution of glacial lakes, which did not show an immediate threat of GLOF (glacial lake outburst flood). However, the field observation in 2001 indicates that many small lakes are developing very rapidly on the major debris-covered glaciers: further monitoring is necessary. Blues sheep is a large wild animal, which is important in conserving endangered species, snow leopard, and in a component of ecotourism resources.

This project demonstrates that conducing geoecological approach based on physical geography is necessary to introduce and develop ecotourism in the Himalaya in terms of safety. This conclusion can be also applied to solve some social issues in mountain areas. Only a small number of Japanese scientists has paid attention to proposal-oriented or problemsolving studies so far. Raising the level of mountain geoecology and increasing the number of geoecologists are of importance in Japan.

\section{Living Space and Local Environment for the Himalayan Peoples: Ecology, Culture, and Development}

The Aim and Discussion of the Symposium IWATA Syuji,* KANO Katsuhiko,** WATANEBE Teiji,*** and TSUKIHARA Toshihiro****

*Tokyo Metropolitan University

**Kanazawa University

***Hokkaido University ****Fukui University

The aim of this symposium organized by us was to have an inter-disciplinary discussion on mountain research with Himalaya as the common area. In the context of Japanese academe of mountain research, it is possible to say that only Himalayan researchers had kept rich tradi- tion to contact and discuss with each other beyond their own disciplines. This was the reason why the Himalaya was chosen as the common area to form a symposium. Nine Japanese and two Nepalese scholars made presentations. Major fields could be listed as geomorphology, geo-ecology, ethno-botany, silviculture, agricultural economy, economic history, cultural anthropology, and cultural geography. Development and environment issues were discussed in each presentation with special reference to peoples' livelihood, their environment and development. Issues brought up for discussion were varied and the time schedule was 